\title{
Bio-Guided Isolation of Antimalarial Metabolites from the Coculture of Two Red Sea Sponge-Derived Actinokineospora and Rhodococcus spp.
}

\author{
Hani A. Alhadrami ${ }^{1,2,+}+^{\mathbb{D}}$, Bathini Thissera ${ }^{3,+}{ }^{\mathbb{D}}$, Marwa H. A. Hassan ${ }^{4} \mathbb{D}$, Fathy A. Behery ${ }^{5,6} \mathbb{D}, \mathrm{Che} \mathrm{Julius} \mathrm{Ngwa}^{7}$, \\ Hossam M. Hassan 4,8 ${ }^{(D)}$, Gabriele Pradel ${ }^{7}$, Usama Ramadan Abdelmohsen ${ }^{9,10, *(\mathbb{D})}$ and Mostafa E. Rateb ${ }^{3, *(\mathbb{D})}$
}

\section{check for} updates

Citation: Alhadrami, H.A.; Thissera, B.; Hassan, M.H.A.; Behery, F.A.; Ngwa, C.J.; Hassan, H.M.; Pradel, G.; Abdelmohsen, U.R.; Rateb, M.E. Bio-Guided Isolation of Antimalarial Metabolites from the Coculture of Two Red Sea Sponge-Derived Actinokineospora and Rhodococcus spp. Mar. Drugs 2021, 19, 109. https:// doi.org/10.3390/md19020109

Academic Editor: Marialuisa Menna

Received: 18 January 2021

Accepted: 9 February 2021

Published: 12 February 2021

Publisher's Note: MDPI stays neutral with regard to jurisdictional claims in published maps and institutional affiliations.

Copyright: (c) 2021 by the authors. Licensee MDPI, Basel, Switzerland. This article is an open access article distributed under the terms and conditions of the Creative Commons Attribution (CC BY) license (https:/ / creativecommons.org/licenses/by/ $4.0 /$ )
1 Department of Medical Laboratory Technology, Faculty of Applied Medical Sciences, King Abdulaziz University, P.O. BOX 80402, Jeddah 21589, Saudi Arabia; hanialhadrami@kau.edu.sa

2 Molecular Diagnostic Laboratory, King Abdulaziz University Hospital, King Abdulaziz University, P.O. BOX 80402, Jeddah 21589, Saudi Arabia

3 School of Computing, Engineering \& Physical Sciences, University of the West of Scotland, Paisley PA1 2BE, UK; bathini.thissera@uws.ac.uk

4 Department of Pharmacognosy, Faculty of Pharmacy, Beni-Suef University, Beni-Suef 62514, Egypt; mh_elsefy@yahoo.com (M.H.A.H.); abuh20050@yahoo.com (H.M.H.)

5 Department of Pharmacognosy, Faculty of Pharmacy, Mansoura University, Mansoura 35516, Egypt; fathy.behery@riyadh.edu.sa

6 Department of Pharmacy, College of Pharmacy, Riyadh Elm University, Riyadh 11681, Saudi Arabia

7 Division of Cellular and Applied Infection Biology, Institute of Zoology, RWTH Aachen University, 52074 Aachen, Germany; ngwa.che@bio2.rwth-aachen.de (C.J.N.); pradel@bio2.rwth-aachen.de (G.P.)

8 Department of Pharmacognosy, Faculty of Pharmacy, Nahda University, Beni-Suef 62514, Egypt

9 Department of Pharmacognosy, Faculty of Pharmacy, Minia University, Minia 61519, Egypt

10 Department of Pharmacognosy, Faculty of Pharmacy, Deraya University, New Minia 61111, Egypt

* Correspondence: usama.ramadan@mu.edu.eg (U.R.A.); Mostafa.Rateb@uws.ac.uk (M.E.R.)

+ These authors are equally contributed.

Abstract: Coculture is a productive technique to trigger microbes' biosynthetic capacity by mimicking the natural habitats' features principally by competition for food and space and interspecies crosstalks. Mixed cultivation of two Red Sea-derived actinobacteria, Actinokineospora spheciospongiae strain EG49 and Rhodococcus sp. UR59, resulted in the induction of several non-traced metabolites in their axenic cultures, which were detected using LC-HRMS metabolomics analysis. Antimalarial guided isolation of the cocultured fermentation led to the isolation of the angucyclines actinosporins $\mathrm{E}(\mathbf{1})$, $\mathrm{H}$ (2), G (3), tetragulol (5) and the anthraquinone capillasterquinone B (6), which were not reported under axenic conditions. Interestingly, actinosporins were previously induced when the axenic culture of the Actinokineospora spheciospongiae strain EG49 was treated with signalling molecule $\mathrm{N}$ acetyl-D-glucosamine (GluNAc); this finding confirmed the effectiveness of coculture in the discovery of microbial metabolites yet to be discovered in the axenic fermentation with the potential that could be comparable to adding chemical signalling molecules in the fermentation flask. The isolated angucycline and anthraquinone compounds exhibited in vitro antimalarial activity and good biding affinity against lysyl-tRNA synthetase (PfKRS1), highlighting their potential developability as new antimalarial structural motif.

Keywords: Actinokineospora; Rhodococcus; co-culture; metabolomics; antimalarial; docking

\section{Introduction}

Exploring microbial forms of communication and utilising them in the production of secondary metabolites is of benefit in the process of natural products drug discovery [1]. Thus far, microbial secondary metabolites remain the major source for antimicrobial agents [2-4]. However, gene sequencing of many microbial genome showed that several species, mainly filamentous bacteria and fungi, apply a considerable part of their genes 
for secondary metabolism (10-15\%) [5,6]. Remarkably, most microorganism genes are silent and have no role during laboratory cultivation [7]. Robert Koch used cultures for only one species of microorganism "axenic growth" to provide an apparent elucidation for this phenomenon of silent genes [8]. Microorganism culture in laboratory included macro- and micro-nutrients, constant temperature, adjusted $\mathrm{pH}$, high water activity, and no contact with other world microbes, and thus a significant part of microorganisms' secondary metabolites, mainly those responsible for interaction, communication, or involving in fights with other species, are not found in microbial metabolites. Therefore, the new approach of co-cultivation provides a massive chance to motivate the silent genes and increase the opportunity to discover cryptic bioactive metabolites [1]. The fortune of "uncultivable" diversity is represented as the "microbial dark matter", the part of microorganisms that was unable to be cultivated in the laboratory until now [1]. The first reported mixed culture was in 1918; it was a coculture of Escherichia coli and Bacillus paratyphosus [9]. Up until now, natural product discovery, biotechnology, and microbiology scientists work on the discovery of coculture or mixed culture experiments to study the difference in the secondary metabolites produced during these trials compared to "axenic growth" [1]. From the examples for coculture and secondary metabolites production, mixed culture of Acremonium sp. and Mycogonerosea that produced new lipoaminopeptides, the acremostatins A-C [10]. Coculture of the marine-derived fungi Aspergillus fumigatus together with two desert bacterial isolates yielded new compounds, namely, luteoride D and pseurotin G [11]. Furthermore, a new $\mathrm{N}$-methoxypyridone was discovered from a mixed fermentation of two endophytic fungi Camporesia sambuci and Epicoccum sorghinum isolated from the fruit of Rhodomyrtus tomentosa plant, collected on the Big Island in Hawaii [12]. New antifungal pulicatin derivatives $\mathrm{H}$ and I were induced following coculturing of plant-derived bacterium Pantoea agglomerans and the fungus Penicillium citrinum [13]. All these examples exemplify that co-cultivation of microorganisms induces new secondary metabolites that can be recommended as an appropriate way to produce diverse bioactive microbial metabolites.

Malaria was identified as a lethal disease caused by Plasmodium parasites, which infect humans through the malaria vector Anopheles mosquitoes. To date, five species of parasites have been identified as causatives of malaria in humans; two of them cause serious infections- $P$. falciparum and $P$. vivax. Studying the malaria cases worldwide revealed that 29 countries accounted for $95 \%$ of malaria cases. The majority of cases $(82 \%)$ and deaths $(94 \%)$ were reported in the WHO African region, followed by the WHO South-East Asia region (10\% cases and 3\% deaths) (https:/ / www.who.int/publications/i/ item/9789240015791, accessed on 30 January 2021). Malaria management and suppression require a complicated method. Up until now, two important antimalarial drugs are used to control infection. These two bitter principle drugs are derived from plants: artemisinin obtained from Artemisia annua L. (4th century, China), and quinine alkaloid obtained from Cinchona sp. (17th century, South America) [14]. The WHO recommends artemisinin combination therapy (ACT) as the first treatment plan in most malarial cases. However, in 2009 , resistance to artemisinin combination therapy was reported. The emerging of drug resistance led to increased malaria cases and an increase in mortality [15]. Thus, the WHO endorsed using a combination of two drugs that work in different mechanisms to control drug resistance. The latest reports from Southeast Asia and India [16] showed the limitation of disease resistance to combination of artemisinin and other drugs as mefloquine and piperaquine [17]. Lacking effective new generation of medicines against malarial invasion, the number of new cases and deaths may rise. Thus, developing antimalarial therapeutics is important to save a large number of lives.

In this work, we discuss the application of co-cultivation of two actinobacteria: Actinokineospora spheciospongiae strain EG49 and Rhodococcus sp. UR59 recovered from Red Sea sponges as a strategy to stimulate silent genes and discover cryptic secondary metabolites within both strains. Additionally, antimalarial-guided fractionation of the bacterial coculture extract led to the isolation and characterisation of a few active metabolites 
against $P$. falciparum. A potential antimalarial target is proposed on the basis of molecular docking experiments against a number of reported targets.

\section{Results and Discussions}

\subsection{Identification of Red Sea Sponge-Associated Actinobacteria}

Two Red sea sponge-associated actinobacteria were isolated and taxonomically identified. Actinokineospora spheciospongiae strain EG49 was previously characterised [18,19]. The other actinobacterial strain was taxonomically identified as Rhodococcus sp. UR59, according to its morphology and its $16 \mathrm{~S}$ rRNA genome sequence and phylogenetic analyses (Figure 1).

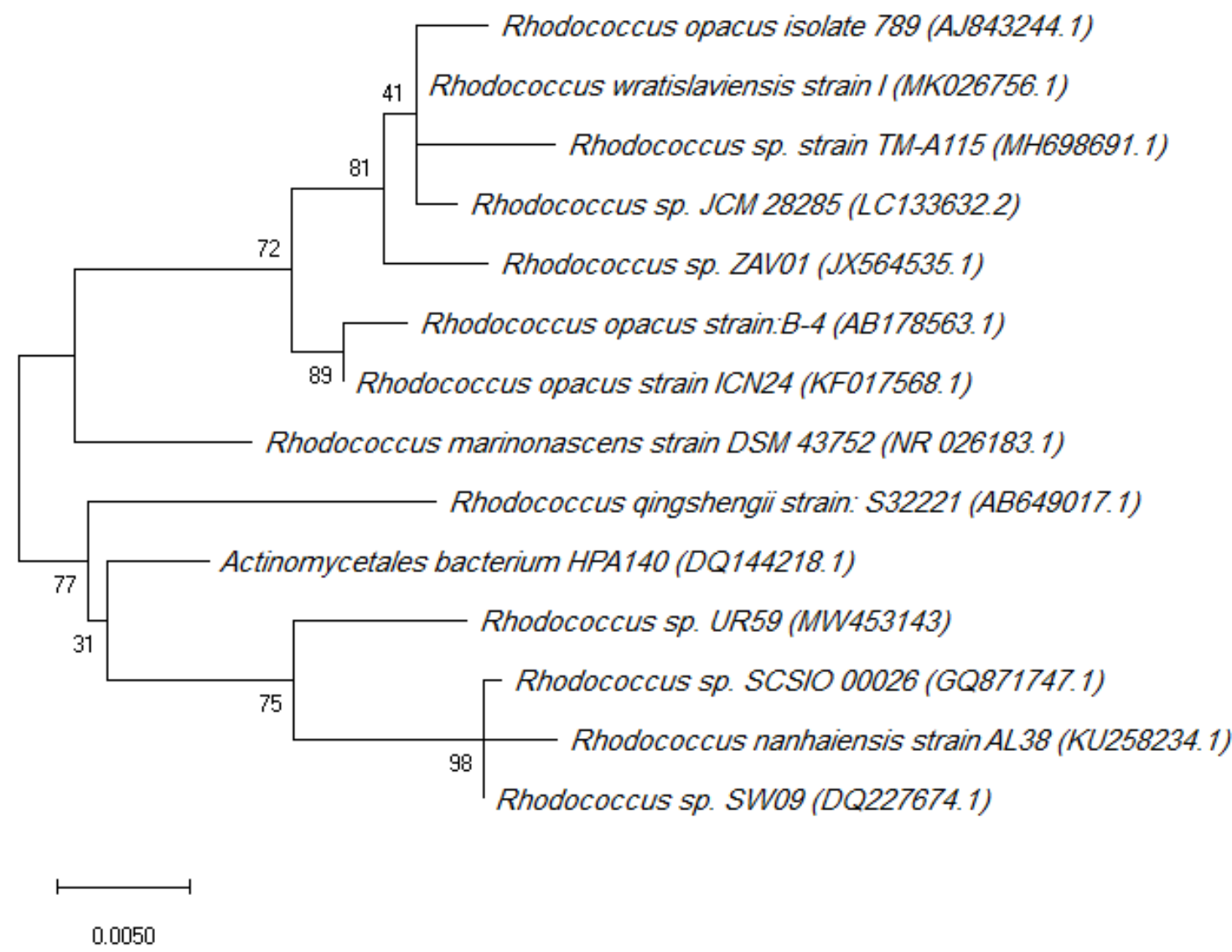

Figure 1. Phylogenetic tree of the Rhodococcus sp. UR59 isolate and the closest relatives in terms of the 16S rRNA gene marker. The accession numbers are indicated in brackets.

2.2. Metabolomics Analysis of the Coculture Extract of Actinokineospora spheciospongiae Strain EG49 and Rhodococcus sp. UR59 Using LC-HRMS

The analysis of the metabolomics data (Table 1) revealed 34 microbial secondary metabolites, of which 9 were detected from Actinokineospora spheciospongiae strain EG49 and the rest from Rhodococcus sp. UR59. Additionally, the analysis revealed the presence of diverse microbial chemical classes, namely, 10 angucyclines, 7 peptides, 3 macrolides, 3 anthraquinones, 2 polyenes, 2 polyethers, 2 phenolics, and 1 glycolipid. The predicted formula $\mathrm{C}_{16} \mathrm{H}_{18} \mathrm{~N}_{2} \mathrm{O}_{4}$ was annotated as mitomycin-K $[20,21]$, whereas $\mathrm{C}_{18} \mathrm{H}_{14} \mathrm{O}_{6}$ was dereplicated as fluostatin-B, an inhibitor of dipeptidyl peptidase III that was previously isolated from Streptomyces sp. TA-3391 [22]. Moreover, the predicted formulas $\mathrm{C}_{32} \mathrm{H}_{33} \mathrm{O}_{15}$ and $\mathrm{C}_{31} \mathrm{H}_{33} \mathrm{O}_{13}$ were dereplicated as actinosporin $\mathrm{A}$ and $\mathrm{C}$, respectively, which were discovered from the culture of Actinokineospora spheciospongiae strain EG49 [23,24]. The formula $\mathrm{C}_{21} \mathrm{H}_{18} \mathrm{O}_{8}$ was dereplicated as daunomycinone, which was reported from Streptomyces coeruleorubid [25]. 
The formulas $\mathrm{C}_{26} \mathrm{H}_{25} \mathrm{O}_{11}$ and $\mathrm{C}_{25} \mathrm{H}_{24} \mathrm{O}_{8}$ were dereplicated as atramycin $\mathrm{A}$ and $\mathrm{B}$, respectively. These isotetracenone metabolites were discovered from Streptomyces atratus BY90 [26]. Additionally, the suggested molecular formula $\mathrm{C}_{18} \mathrm{H}_{12} \mathrm{O}_{5}$ was dereplicated as lagumycin B, which was previously isolated from Micromonospora sp. [27], while the formula $\mathrm{C}_{16} \mathrm{H}_{12} \mathrm{O}_{5}$ was dereplicated as the isoflavonoid kakkatin that was reported from the soil-derived Streptomyces strain YIM GS3536. Moreover, it was discovered in another terrestrial Streptomyces sp. GW39/1530 [28,29]. Furthermore, the molecular formula $\mathrm{C}_{9} \mathrm{H}_{9} \mathrm{NO}_{3}$ was dereplicated as erbstatin, a simple dehydrotyrosine derivative isolated from Streptomyces amnkusaensis [30,31]. Additionally, the molecular formula $\mathrm{C}_{36} \mathrm{H}_{48} \mathrm{~N}_{2} \mathrm{O}_{8}$ was dereplicated as ansatrienin A, previously detected in Streptomyces collinus [32]. Moreover, the formulas $\mathrm{C}_{25} \mathrm{H}_{47} \mathrm{~N}_{5} \mathrm{O}_{4}, \mathrm{C}_{26} \mathrm{H}_{49} \mathrm{~N}_{5} \mathrm{O}_{4}$, and $\mathrm{C}_{28} \mathrm{H}_{53} \mathrm{~N}_{5} \mathrm{O}_{4}$ were dereplicated as cyclic tetrapeptides rhodopeptin $\mathrm{C} 1, \mathrm{C} 2$, and $\mathrm{B} 5$, respectively, which were formerly reported in Rhodococcus sp. [33,34]. The formula $\mathrm{C}_{32} \mathrm{H}_{48} \mathrm{~N}_{6} \mathrm{O}_{9}$ was dereplicated as the peptide actinoramide $\mathrm{B}$, which was detected in a marine bacterium highly corelated to the genus Streptomyces [35]. Likewise, the formula $\mathrm{C}_{17} \mathrm{H}_{26} \mathrm{O}_{4}$ was dereplicated as cineromycin- $\mathrm{B}$ antibiotic that showed significant MRSA inhibition, which was isolated from the actinomycetales strain INA 2770 [36]. The formula $\mathrm{C}_{19} \mathrm{H}_{27} \mathrm{~N}_{5} \mathrm{O}_{7}$ was annotated as heterobactin B, a siderophore discovered from Rhodococcus erythropolis IGTS8 [37], while the formula $\mathrm{C}_{26} \mathrm{H}_{39} \mathrm{NO}_{5}$ was dereplicated as piericidin- $\mathrm{F}$, which was reported from Streptomyces sp. CHQ-64 [38]. Additionally, the formula $\mathrm{C}_{27} \mathrm{H}_{39} \mathrm{NO}_{7}$ was annotated as migrastatin, which was reported as a tumour cell migration inhibitor and isolated from Streptomyces sp. MK92943F1 [39]. Moreover, the formula $\mathrm{C}_{24} \mathrm{H}_{46} \mathrm{~N}_{6} \mathrm{O}_{8}$ was dereplicated as proferrioxamine-A1, a siderophore isolated from Streptomyces xinghaiensis NRRL B-24674T [40]. Furthermore, the formula $\mathrm{C}_{23} \mathrm{H}_{38} \mathrm{O}_{5}$ was dereplicated as the 16-membered lactone protylonolide, which was identified as the metabolite of mycaminose idiotroph that has been obtained from Streptomyces fradiae KA-427 [41]. Moreover, the formula $\mathrm{C}_{37} \mathrm{H}_{62} \mathrm{O}_{11}$ was dereplicated as the polyether 26-deoxylaidlomycin isolated from Streptoverticillium olivoreticuli IMET 43,782 [42], while the suggested formula $\mathrm{C}_{35} \mathrm{H}_{58} \mathrm{O}_{10}$ was dereplicated as macrolide kaimonolide B, which was discovered in Streptomyces sp. no. 4155 and shown to significantly inhibit plant growth [43]. Furthermore, the formula $\mathrm{C}_{25} \mathrm{H}_{44} \mathrm{O}_{7}$ was dereplicated as 8,15-dideoxylankanolide, which was reported in Streptomyces rochei 7434AN4 [44]. The molecular formula $\mathrm{C}_{34} \mathrm{H}_{60} \mathrm{O}_{10}$ was identified as the polyether antibiotic ferensimycin- $\mathrm{A}$, previously discovered in Streptomyces sp. no. 5057 [45]. Likewise, the formula $\mathrm{C}_{26} \mathrm{H}_{46} \mathrm{~N}_{6} \mathrm{O}_{5}$ was identified as the cytotoxic peptide lucentamycin $\mathrm{C}$, which was reported from a marinederived actinomycete Nocardiopsis lucentensis CNR-712 [46]. Finally, the formula $\mathrm{C}_{50} \mathrm{H}_{92} \mathrm{O}_{14}$ was dereplicated as glucolipsin-A, a glucokinase activator that has been isolated from Streptomyces puvpuvogenisclevoticus [47].

It is worth noting that the compounds listed in Table 1 were traced in the LC-HRESIMS analysis of the coculture extract. The producing strain for each compound was predicted on the basis of literature. However, mitomycin- $\mathrm{K}, 8,15$-dideoxylankanolide, piericidin- $\mathrm{F}$, migrastatin, kaimonolide $\mathrm{B}$, rhodopeptin $\mathrm{C} 1$, rhodopeptin $\mathrm{C} 2$, and rhodopeptin $\mathrm{B} 5$ were also traced in the axenic culture of Rhodococcus sp. UR59. Additionally, actinosporins A and $\mathrm{C}$, and UK-2B were also traced in the axenic culture of Actinokineospora spheciospongiae strain EG49. All other reported metabolites in Table 1 were not traced in the axenic cultures and were induced during the coculture fermentation. 
Table 1. Metabolomics analysis of the coculture extract of Actinokineospora spheciospongiae strain EG49 and Rhodococcus sp. UR59.

\begin{tabular}{|c|c|c|c|c|c|c|c|c|c|}
\hline$\underset{\text { (min) }}{\mathrm{Rt}}$ & $\begin{array}{c}m / z \\
{[\mathbf{M}-\mathbf{H}]^{-}}\end{array}$ & $\begin{array}{c}m / z \\
{[\mathbf{M}+\mathbf{H}]^{+}}\end{array}$ & $\begin{array}{l}\text { Molecular } \\
\text { Formula }\end{array}$ & Tentative Identification & $\begin{array}{l}\text { Strain } \\
\text { EG49 }\end{array}$ & $\begin{array}{l}\text { Strain } \\
\text { UR59 }\end{array}$ & Coculture & Bioactivity & Ref. \\
\hline 2.47 & \multirow{7}{*}{657.1821} & 303.1341 & $\mathrm{C}_{16} \mathrm{H}_{18} \mathrm{~N}_{2} \mathrm{O}_{4}$ & Mitomycin-K & - & + & + & antitumor & [20] \\
\hline 2.91 & & 327.0866 & $\mathrm{C}_{18} \mathrm{H}_{14} \mathrm{O}_{6}$ & Fluostatin-B & - & - & + & antinociceptive & {$[22]$} \\
\hline 2.94 & & & $\mathrm{C}_{32} \mathrm{H}_{33} \mathrm{O}_{15}$ & Actinosporin A & + & - & + & anti-trypanosomal & [23] \\
\hline 2.96 & & 613.1926 & $\mathrm{C}_{31} \mathrm{H}_{33} \mathrm{O}_{13}$ & Actinosporin C & + & - & + & antioxidant & {$[24]$} \\
\hline 2.99 & & 399.1075 & $\mathrm{C}_{21} \mathrm{H}_{18} \mathrm{O}_{8}$ & Daunomycinone & - & - & + & - & {$[48]$} \\
\hline 3.04 & & 599.2125 & $\mathrm{C}_{31} \mathrm{H}_{34} \mathrm{O}_{12}$ & Actinosporin $\mathrm{F}$ & - & - & + & - & [49] \\
\hline 3.08 & & 469.1492 & $\mathrm{C}_{25} \mathrm{H}_{24} \mathrm{O}_{9}$ & Actinosporin E & - & - & + & - & [49] \\
\hline 3.11 & \multirow{4}{*}{513.1399} & 467.1336 & $\mathrm{C}_{25} \mathrm{H}_{22} \mathrm{O}_{9}$ & Actinosporin $\mathrm{H}$ & - & - & + & - & [49] \\
\hline 3.15 & & & $\mathrm{C}_{26} \mathrm{H}_{25} \mathrm{O}_{11}$ & Atramycin A & - & - & + & antitumor & [26] \\
\hline 3.25 & & 451.1389 & $\mathrm{C}_{25} \mathrm{H}_{22} \mathrm{O}_{8}$ & Actinosporin $G$ & - & - & + & - & [49] \\
\hline 3.30 & & 309.0757 & $\mathrm{C}_{18} \mathrm{H}_{12} \mathrm{O}_{5}$ & Lagumycin B & - & - & + & anticancer & [27] \\
\hline 3.76 & 178.0499 & & $\mathrm{C}_{9} \mathrm{H}_{9} \mathrm{NO}_{3}$ & Erbstatin & - & - & + & anticancer & [30] \\
\hline 3.81 & 635.3315 & & $\mathrm{C}_{36} \mathrm{H}_{48} \mathrm{~N}_{2} \mathrm{O}_{8}$ & Ansatrienin A & - & - & + & antifungal & [32] \\
\hline 3.93 & 192.0655 & & $\mathrm{C}_{10} \mathrm{H}_{11} \mathrm{NO}_{3}$ & Spoxazomicin C & - & - & + & anti-trypanosomal & {$[50]$} \\
\hline 4.12 & \multirow{3}{*}{293.1749} & 661.3568 & $\mathrm{C}_{32} \mathrm{H}_{48} \mathrm{~N}_{6} \mathrm{O}_{9}$ & Actinoramide B & - & - & + & antimalarial & [51] \\
\hline 4.17 & & & $\mathrm{C}_{17} \mathrm{H}_{26} \mathrm{O}_{4}$ & Cineromycin-B & - & - & + & antibacterial & [52] \\
\hline 4.54 & & 438.1974 & $\mathrm{C}_{19} \mathrm{H}_{27} \mathrm{~N}_{5} \mathrm{O}_{7}$ & Heterobactin B & - & - & + & siderophore & [37] \\
\hline 6.41 & 451.1391 & & $\mathrm{C}_{25} \mathrm{H}_{24} \mathrm{O}_{8}$ & Atramycin B & - & - & + & antitumor & [26] \\
\hline 6.34 & 444.2744 & & $\mathrm{C}_{26} \mathrm{H}_{39} \mathrm{NO}_{5}$ & Piericidin-F & - & + & + & anticancer & [38] \\
\hline 6.91 & 488.2649 & & $\mathrm{C}_{27} \mathrm{H}_{39} \mathrm{NO}_{7}$ & Migrastatin & - & + & + & anticancer & [53] \\
\hline 7.24 & \multirow{14}{*}{393.2640} & 547.3455 & $\mathrm{C}_{24} \mathrm{H}_{46} \mathrm{~N}_{6} \mathrm{O}_{8}$ & Proferrioxamine-A1 & - & - & + & siderophore & {$[40]$} \\
\hline 7.40 & & & $\mathrm{C}_{23} \mathrm{H}_{38} \mathrm{O}_{5}$ & Protylonolide & - & - & + & antibiotic & [41] \\
\hline 7.58 & & 683.4347 & $\mathrm{C}_{37} \mathrm{H}_{62} \mathrm{O}_{11}$ & 26-Deoxylaidlomycin & - & - & + & antibacterial & [54] \\
\hline 7.76 & & 482.3687 & $\mathrm{C}_{25} \mathrm{H}_{47} \mathrm{~N}_{5} \mathrm{O}_{4}$ & Rhodopeptin C1 & - & + & + & Antifungal & [33] \\
\hline 8.15 & & 639.4084 & $\mathrm{C}_{35} \mathrm{H}_{58} \mathrm{O}_{10}$ & Kaimonolide B & - & + & + & $\begin{array}{l}\text { plant growth } \\
\text { inhibitor }\end{array}$ & [43] \\
\hline 9.09 & & 496.3846 & $\mathrm{C}_{26} \mathrm{H}_{49} \mathrm{~N}_{5} \mathrm{O}_{4}$ & Rhodopeptin C2 & - & + & + & antifungal & [34] \\
\hline 9.14 & & 524.4156 & $\mathrm{C}_{28} \mathrm{H}_{53} \mathrm{~N}_{5} \mathrm{O}_{4}$ & Rhodopeptin B5 & - & + & + & antifungal & {$[34]$} \\
\hline 9.80 & & 315.0865 & $\mathrm{C}_{17} \mathrm{H}_{14} \mathrm{O}_{6}$ & Capillasterquinone B & - & - & + & $\begin{array}{l}\text { NO production } \\
\text { inhibitor }\end{array}$ & [55] \\
\hline 9.81 & & 305.0810 & $\mathrm{C}_{19} \mathrm{H}_{12} \mathrm{O}_{4}$ & Tetrangulol & - & - & + & antibiotic & [56] \\
\hline 9.98 & & 457.3141 & $\mathrm{C}_{25} \mathrm{H}_{44} \mathrm{O}_{7}$ & 8,15-Dideoxylankanolide & - & + & + & - & {$[44]$} \\
\hline 10.22 & & 527.2022 & $\mathrm{C}_{27} \mathrm{H}_{31} \mathrm{~N}_{2} \mathrm{O}_{9}$ & UK-2B & + & - & + & antifungal & {$[57]$} \\
\hline 11.01 & & 629.4242 & $\mathrm{C}_{34} \mathrm{H}_{60} \mathrm{O}_{10}$ & Ferensimycin-A & - & - & + & antibiotic & {$[45]$} \\
\hline 11.23 & & 523.3601 & $\mathrm{C}_{26} \mathrm{H}_{46} \mathrm{~N}_{6} \mathrm{O}_{5}$ & Lucentamycin C & - & - & + & anticancer & [46] \\
\hline 11.28 & & 917.6546 & $\mathrm{C}_{50} \mathrm{H}_{92} \mathrm{O}_{14}$ & Glucolipsin-A & - & - & + & $\begin{array}{l}\text { glucokinase } \\
\text { activator }\end{array}$ & [47] \\
\hline
\end{tabular}

\subsection{Identification of the Isolated Compounds (1-8)}

Chemical structures of the purified metabolites 1-8 from the coculture were assigned on the basis of comparing the LC-HRESIMS analysis, 1D and 2D NMR spectral data, and optical rotation measurements to the published literature (Figure 2). Accordingly, compounds 1-3 have been previously isolated from Actinokineospora spheciospongiae strain EG49 and identified as the angucyclinone antibiotics actinosporin E, H, and G, respectively, through the activation of their cryptic gene cluster by $\mathrm{N}$-acetylglucosamine [50]. Compound 4 was assigned as spoxazomicin C of the pyochelin family of antibiotics, which was previously isolated from the culture broth of the endophyte Streptosporangium oxazolinicum K07-0460T [51]. In contrast, compound 5 was previously identified as the angucyclinone antibiotic tetrangulol, which was previously isolated from Streptomyces rimosus [58] and recently from Amycolatopsis sp. HCa1 [59]. Compound 6 was previously discovered as capillasterquinone $\mathrm{B}$, an anthraquinone that was isolated from the crinoid Capillaster multiradiatus [57]. Moreover, compound 7 was identified as L-tryptophanamide. We propose it as an artefact as it was not traced in the LC-MS analysis of either the axenic or the coculture extracts, and thus it was probably generated during the fractionation and purification process. Finally, compound 8 was isolated from Streptomyces sp. 517-02 [57] and identified as UK-2B, an antifungal antibiotic with similarity in structure to antimycin A [60]. 

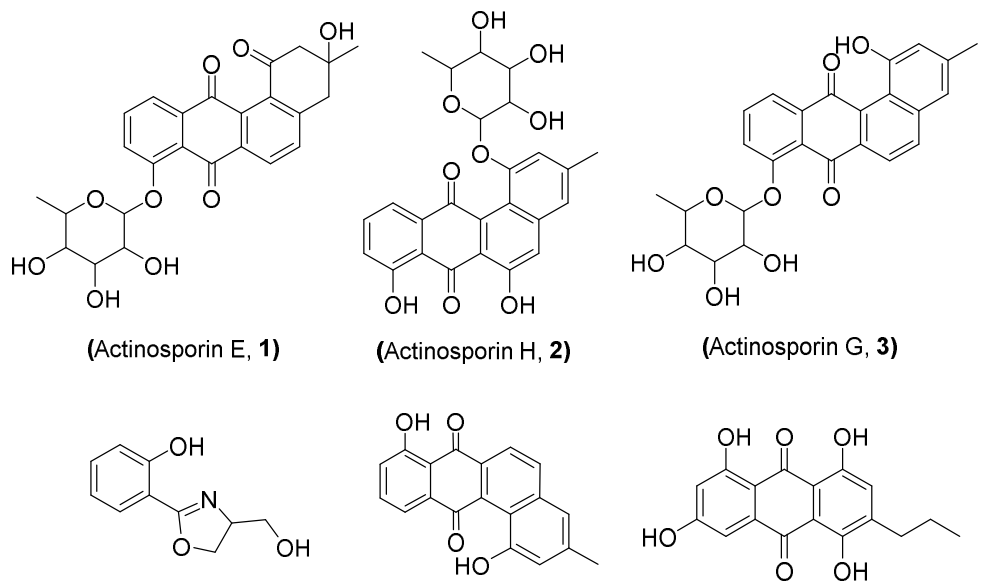

(Spoxazomicin C, 4)

(Tetrangulol, 5)

(capillasterquinone $\mathrm{B}, \mathbf{6}$ )

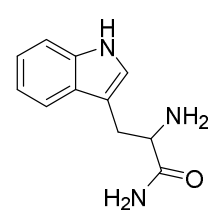

(L-Tryptopanamide, 7)

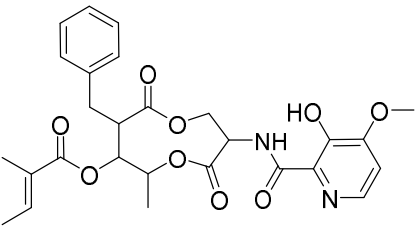

(UK-2B, 8)

Figure 2. Compounds isolated from the coculture of Actinokineospora spheciospongiae strain EG49 and Rhodococcus sp. UR59.

The same Actinokineospora spheciospongiae strain EG49 was subjected to N-acetyl-Dglucosamine (GluNAc)-mediated silent gene activation to produce new actinosporins $\mathrm{E}-\mathrm{H}$, the same actinosporins $\mathrm{E}(\mathbf{1}), \mathrm{G}(3)$, and $\mathrm{H}$ (2) discussed here under coculture and aglycone angucycline tetrangulol (5), which was not reported from the axenic culture treated with GluNAc [50]. The amino sugar GluNAc is a signalling molecule that can induce microbial secondary metabolism. It is present as a cell wall component in peptidoglycan or chitin in the bacterial or fungal cell wall, respectively $[60,61]$. Having observed a similar induction when Actinokineospora spheciospongiae strain EG49 was cocultured with Rhodococcus sp. UR59, we can assume that Rhodococcus sp. UR59 directed the biosynthesis of actinosporins in a similar way to GluNAc. This could be as exudation of GluNAc by one of the species into the coculture environment to trigger antibiotic production more likely from Rhodococcus sp. UR59 as defence molecules. The studies further support this and demonstrated that GluNAc is secreted by bacteria under malnourished conditions to signal antibiotic production against opposite competitors in the vicinity [62]. However, this requires further studies on the coculture medium to identify excreted GluNAc or compounds with similar signalling function.

\subsection{Antimalarial Screening}

Angucyclines are microbial secondary metabolites known as promising antimicrobial, anticancer, and antimalarial agents [63-65]. The core structure of angucyclines is characterised by a benz $[\alpha]$ anthracene ring, an angular tetracycline ring system [60]. The reported angucyclines can be categorised as aglycones such as saccharosporones A, B, and $C$ [60], and glycosylated angucyclines such as pseudonocardones $A-C$ [63] and urdamycinone $\mathrm{E}$, urdamycinone $\mathrm{G}$, and dehydroxyaquayamycin isolated from fungal and bacterial strains [62]. However, different antimalarial activity profiles between aglycones and glycosylated angucyclines have not been explained.

The potential antiparasitic effectiveness of the angucycline scaffold and the promising antimalarial effect exhibited by the total extract of the coculture of Actinokineospora spheciospongiae strain EG49 and Rhodococcus sp. UR59 ( $\mathrm{IC}_{50}$ value of $0.13 \mu \mathrm{g} / \mathrm{mL}$, Table 2) when screened 
against Plasmodium falciparum have encouraged us to perform large-scale coculture fermentation. Large-scale fermentation followed by liquid-liquid fractionation and HPLC purification of the active sub-fraction led to the isolation of eight metabolites. The antimalarial screening of the isolated compounds indicated that the angucycline glycosides 1-3 and aglycone 5 and the anthraquinone 6 exhibited antimalarial effect with $\mathrm{IC}_{50}$ values in the range of $9-13.5 \mu \mathrm{g} / \mathrm{mL}$ in comparison to the $\mathrm{IC}_{50}$ value of the positive control chloroquine $(0.022 \mu \mathrm{g} / \mathrm{mL})$. The activity of the compounds $1-3,5$, and $\mathbf{6}$ was further studied by docking against a few known drug targets to suggest these compounds as potential leads to be developed for enhanced activity. It worth noting that the isolated molecules did not show the expected antimalarial activity, which could be attributed to either the synergistic effect of microbial metabolites in the coculture extract or the presence of minor molecules that were too scarce to be isolated even after large-scale fermentation.

Table 2. Antimalarial effect of the bacterial coculture derived metabolites.

\begin{tabular}{cc}
\hline Compound & IC $_{\mathbf{5 0}}$ Values $(\boldsymbol{\mu g} / \mathbf{m L})^{\mathbf{1}}$ \\
\hline Coculture extract & 0.13 \\
$\mathbf{1}$ & 12.6 \\
$\mathbf{2}$ & 13.6 \\
$\mathbf{3}$ & 11.2 \\
$\mathbf{4}$ & $>50$ \\
$\mathbf{5}$ & 9.7 \\
$\mathbf{6}$ & 9.2 \\
$\mathbf{7}$ & $>50$ \\
$\mathbf{8}$ & $>50$ \\
Chloroquine & 0.022 \\
\hline
\end{tabular}

${ }^{1}$ Average of two independent runs.

\subsection{Docking Analysis}

Compounds $(\mathbf{1}-\mathbf{3}, \mathbf{5}, \mathbf{6})$ that showed inhibitory activity against $P$. falciparum were subjected to molecular docking experiments against a number of reported malaria targets, e.g., NADH:ubiquinone oxidoreductase (PDB: 5JWA), Kelch protein (PDB: 4YY8), P. falciparum protein kinase (PDB: 1V0P), NADH dehydrogenase 2 (PDB:4PD4), and lysyl-tRNA synthetase (PDB:6AGT). They achieved the best scores (binding energy -8.5 to $-9.1 \mathrm{kcal} / \mathrm{mol}$ ) against the later target, lysyl-tRNA synthetase (PfKRS1). Moreover, they exhibited binding mode inside the active site compared to the co-crystalised ligand [66]. As shown in Table 3 and Figure 3, these compounds exhibited multiple interactions with several amino acids inside the enzyme's active site, where ARG-330, HIS-338, GLU-500, ARG-559, and PHE-342 were the most common interacting ones. Hence, this attractive scaffold can be utilised in the future design of antimalarial therapeutics targeting PfKRS1 (Table 3). Antimalarial effect of the bacterial coculture derived metabolites.

Table 3. Binding scores and interacting amino acid residues with compounds $\mathbf{1}-\mathbf{3}, \mathbf{5}$, and $\mathbf{6}$ inside the lysyl-tRNA synthetase (PfKRS1)'s active site.

\begin{tabular}{cccc}
\hline Compound & $\begin{array}{c}\text { Binding Energy } \\
\mathbf{( k c a l / m o l )}\end{array}$ & H-Bonding & Hydrophobic Interactions \\
\hline $\mathbf{1}$ & -8.9 & ARG-330 & ALA-446, GLU-500, LYS-607 \\
$\mathbf{2}$ & -8.3 & ASP-450, SER-454, MET-475 & ARG-330, HIS-338, ASP-450, GLU-458, GLU-500 \\
$\mathbf{3}$ & -10.3 & GLU-493 & ARG-330, PHE-342, ASP-450, ARG-559 \\
$\mathbf{6}$ & -9.1 & GLU-500, THR-337 & ARG-330, HIS-338, PHE-342, ARG-559 \\
Co-crystalised ligand & -9.0 & ARG-330, ASN-339 & ARG-330, HIS-338, PHE-342, GLU-500, ARG-559, LYS-607 \\
\hline
\end{tabular}




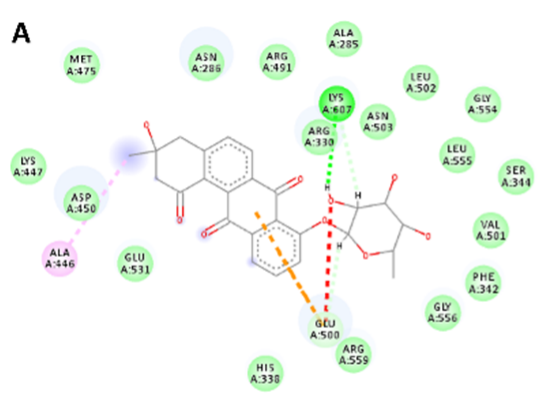

D

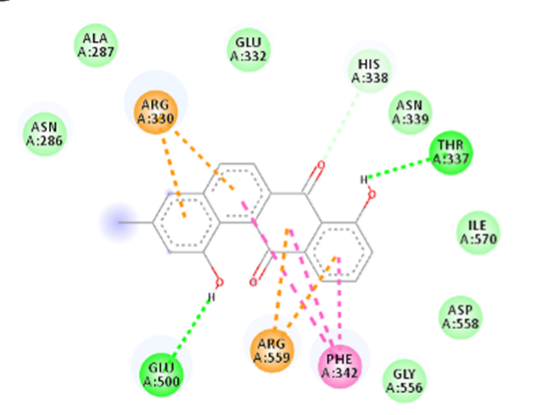

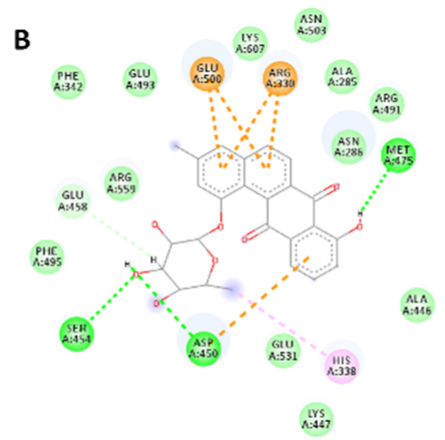

$\mathbf{E}$

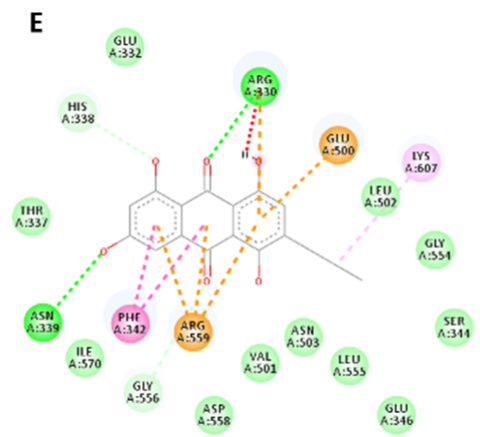

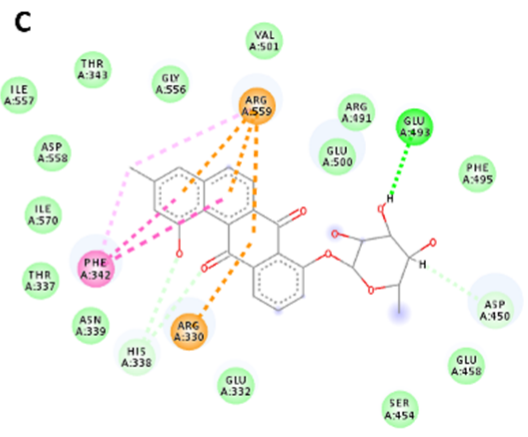

$\mathbf{F}$

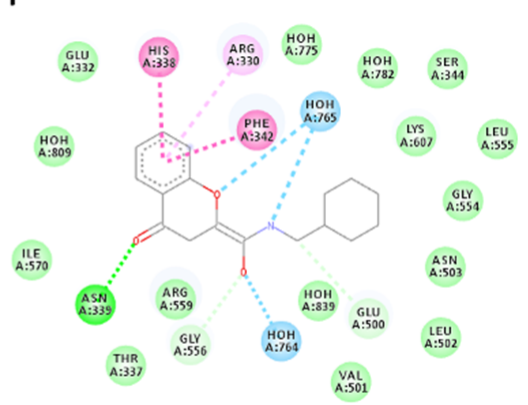

Figure 3. Binding modes of compounds 1-3, 5, and 6 ((A-E) respectively) together with the co-crystalised ligand (F) inside PfKRS's active site. Dashed lines indicate interactions between each ligand and the active site's amino acid residues. Green colour indicates H-bonding; orange colour indicates $\pi$-anion or $\pi$-cation interactions; pink colour indicates hydrophobic interactions.

\section{Materials and Methods}

\subsection{General Experimental}

Extract purification was conducted by preparative Agilent 1100 series HPLC equipped with gradient pump and DAD using a reversed-phase Sunfire $(C 18,5 \mu \mathrm{m}, 10 \times 250 \mathrm{~mm}$, serial no. 226130200125). All 1D and 2D NMR spectral data were acquired using a JEOL ECZ-R500 NMR spectrometer equipped with a Royal $5 \mathrm{~mm}$ combined broadband and inverse probe. Thermo LTQ Orbitrap coupled to an HPLC system was utilised to acquire HRESIMS data using capillary temperature of $260^{\circ} \mathrm{C}$, capillary voltage of $45 \mathrm{~V}$, sheath gas flow rate of 40-50 arbitrary units, auxiliary gas flow rate of 10-20 arbitrary units, spray voltage of $4.5 \mathrm{kV}$, and mass range of 100-2000 amu (maximal resolution of 60,000). Optical rotations and UV spectra acquisition were acquired using a Perkin-Elmer 343 polarimeter and Perkin-Elmer Lambda2 UV-VIS spectrometer, respectively.

\subsection{Actinomycetes Isolation}

Callyspongia sp. was collected from Hurghada (Red Sea, Egypt) at a depth of $5 \mathrm{~m}$ and latitude $27^{\circ} 17^{\prime} 01.0^{\prime \prime} \mathrm{N}$ and longitude $33^{\circ} 46^{\prime} 21.0^{\prime \prime} \mathrm{E}$. The sponge specimen was identified by Prof. El-Sayd Abed El-Aziz (Department of Invertebrates Lab., National Institute of Oceanography and Fisheries, Egypt). The sponge was transported in a plastic bag in seawater to the laboratory and washed thoroughly with sterile seawater. The surface sterilised specimen was cut into pieces of $\approx 1 \mathrm{~cm}^{3}$, followed by vigorous homogenising with 10 volumes of sterile seawater in a pre-sterilised mortar. Serially diluted supernatant $\left(10^{-1}, 10^{-2}, 10^{-3}\right)$ was subsequently plated on to the sterile agar plates. For the isolation of different actinomycetes, we used M1, ISP2, and marine agar (MA) media were used [18]. The isolation of slow-growing actinomycetes was performed by supplementing all media with filtered $25 \mu \mathrm{g} / \mathrm{mL}$ nalidixic acid, $25 \mu \mathrm{g} / \mathrm{mL}$ nystatin, and $100 \mu \mathrm{g} / \mathrm{mL}$ cycloheximide. The inoculated plates were stored in an incubator for $6-8$ weeks at $30^{\circ} \mathrm{C}$. Subculturing of distinct colony morphotypes resulted in pure strains. Rhodococcus sp. UR59 was cultured on ISP2 medium and preserved in $20 \%$ glycerol at $-80{ }^{\circ} \mathrm{C}$. On the other hand, 
Actinokineospora spheciospongiae strain EG49 was previously recovered and identified from the Red Sea sponge Spheciospongia vagabunda [18].

\subsection{Molecular Identification and Phylogenetic Analysis}

With reference to Hentschel et al., we carried out 16S rRNA gene amplification, cloning, and sequencing using 27F and 1492RRNA as universal primers [18]. By using the Pintail programme, we identified chimeric sequences [67]. The sequence's genus level affiliation was validated using the Project Classifier of the Ribosomal Database. All the sequences were classified at the genus level by the RDP Classifier (g 16srrna, $\mathrm{f}$ allran) and confirmed with the SILVA Incremental Aligner (SINA) [68]. Using the SINA Web Aligner, an alignment was determined again (variability profile: bacteria). The Gap-only position with trimALL was eliminated (-noallgaps). The best fitting model was initially calculated for phylogenetic tree construction with the Model Generator. To produce the phylogenetic tree, we applied RAxML (-f a-m GTRGAMMA-x 12345-p 12345 -\# 1000) and the estimated model with 1000 bootstrap resamples. With Interactive Tree of Life (ITOL) [69], visualisation was achieved. The BLAST with the accession number MW453143 was deposited at Genebank.

\subsection{Co-Cultivation and Extract Preparation}

Rhodococcus sp. UR59 and Actinokineospora spheciospongiae strain EG49 were cultivated on liquid media M1 and ISP2 as axenic and cocultures. A total of $20 \mathrm{~mL}$ of 3-day-old culture of Rhodococcus sp. was used for large scale fermentation. Rhodococcus sp. UR59 was transferred to $20 \times 2 \mathrm{~L}$ Erlenmeyer flasks containing $1 \mathrm{~L}$ of ISP2 medium pre-inoculated with $20 \mathrm{~mL}$ of 4-day-old Actinokineospora spheciospongiae strain EG49 and left for 7 days at $25^{\circ} \mathrm{C}$ and $180 \mathrm{rpm}$ in a shaker incubator. After fermentation, the culture was filtered, and the supernatant was extracted twice with ethyl acetate $(1.5 \mathrm{~L}$ each) followed by evaporation under vacuum to provide the ethyl acetate extract $(850 \mathrm{mg})$.

\subsection{Metabolic Profiling}

For mass spectrometry analysis, the dry ethyl acetate extracts from different microbial and coculture samples were dissolved in $\mathrm{MeOH}$ at $1 \mathrm{mg} / \mathrm{mL}$ and subjected to metabolic analysis using LC-HRESIMS according to Abdelmohsen et al. [23]. An Acquity UPLC system coupled to a Synapt G2 HDMS qTOF hybrid mass spectrometer (Waters, Milford, CT, USA) was used to acquire the HRMS data using capillary temperature at $320^{\circ} \mathrm{C}$, spray voltage at $4.5 \mathrm{kV}$, and mass range of $\mathrm{m} / \mathrm{z} 150-1500$; both positive and negative ESI modes were applied. The MS was processed using MZmine 2.20 on the basis of the defined parameters [23]. The chromatogram builder and chromatogram deconvolution were detected and followed by mass ion peaks. The isotopes were differentiated by grouper isotopic peaks and the missing peaks were depicted using the gap-filling peak finder. Then, molecular formula prediction and peak identification were conducted from the processed positive and negative ionisation mode datasets. Finally, the peaks were dereplicated against the Dictionary of Natural Products (DNP) database.

\subsection{Metabolites Isolation}

The crude co-fermentation ethyl acetate (EtOAc) $(850 \mathrm{mg})$ was chromatographed on Sephadex LH-20 $(32-64 \mu \mathrm{m}, 100 \times 25 \mathrm{~mm})$ column using an 80:20 MeOH/ $\mathrm{H}_{2} \mathrm{O}$ eluent in order to obtain 5 fractions (Fr.1-Fr.6). The third bioactive fraction $(300 \mathrm{mg})$ was then chromatographed using silica gel column with a gradient elution starting at DCM/EtOAc (100:0 to $0: 100)$ then $100 \% \mathrm{MeOH}$ to obtain 8 sub-fractions. The active subfractions 4 and 5 were combined $(85 \mathrm{mg})$ and further subjected to semi preparative HPLC purification (Sunfire, C18, $5 \mu \mathrm{m}, 10 \times 250 \mathrm{~mm}$ ) with a gradient of $20 \%-100 \% \mathrm{CH}_{3} \mathrm{CN}$ in $\mathrm{H}_{2} \mathrm{O}$ over $30 \mathrm{~min}$ and $10 \mathrm{~min}$ at $100 \% \mathrm{CH}_{3} \mathrm{CN}$ at $1.5 \mathrm{~mL} / \mathrm{min}$ flow rate to yield compound $7\left(\mathrm{t}_{\mathrm{R}} 9.6 \mathrm{~min}\right.$, $7.5 \mathrm{mg}), 2\left(\mathrm{t}_{\mathrm{R}} 10.7 \mathrm{~min}, 4.5 \mathrm{mg}\right), 3\left(\mathrm{t}_{\mathrm{R}} 11.2 \mathrm{~min}, 2.5 \mathrm{mg}\right), 4\left(\mathrm{t}_{\mathrm{R}} 15.2 \mathrm{~min}, 2.8 \mathrm{mg}\right), \mathbf{5}\left(\mathrm{t}_{\mathrm{R}} 18.3 \mathrm{~min}\right.$, $2.1 \mathrm{mg}), \mathbf{1}\left(\mathrm{t}_{\mathrm{R}} 24.6 \mathrm{~min}, 3.2 \mathrm{mg}\right), \mathbf{6}\left(\mathrm{t}_{\mathrm{R}} 27.2 \mathrm{~min}, 3.8 \mathrm{mg}\right)$, and $8\left(\mathrm{t}_{\mathrm{R}} 31.3 \mathrm{~min}, 1.5 \mathrm{mg}\right)$. 


\subsection{Antimalarial Screening}

The Malstat assay was used as mentioned earlier to assess the compounds' antimalarial effect $[70,71]$. The compounds were dissolved in DMSO (Sigma Aldrich, Taufkirchen, Germany) at concentrations ranging from $50 \mu \mathrm{g} / \mathrm{mL}$ to $0.4 \mu \mathrm{g} / \mathrm{mL}$, and synchronised P. falciparum 3D7 ring stage cultures were placed in duplicate at a parasite level of $1 \%$ in 96-well plates (200 $\mu \mathrm{L} /$ well). Chloroquine (CQ; Sigma Aldrich, Taufkirchen, Germany) was used as a positive control. The $P$. falciparum 3D7 parasite was cultured with the compounds at $37{ }^{\circ} \mathrm{C}$ in $5 \% \mathrm{O}_{2}, 5 \% \mathrm{CO}_{2}$, and $90 \% \mathrm{~N}_{2}$ for $72 \mathrm{~h}$. After this, $20 \mu \mathrm{L}$ was transferred to $100 \mu \mathrm{L}$ of the Malstat reagent $(0.1 \%$ Triton X-100, $1 \mathrm{~g}$ of L-lactate, $0.33 \mathrm{~g}$ Tris, and $33 \mathrm{mg}$ of APAD (3-acetylpyridine adenine dinucleotide; Taufkirchen, Germany)) dissolved in $100 \mathrm{~mL}$ of distilled water ( $\mathrm{pH} 9.0$ ) in a 96-well microtiter plate. The plasmodial lactate dehydrogenase (LDH) activity was then evaluated by adding to the Malstat reaction $20 \mu \mathrm{L}$ of a 1:1 mixture of diaphorase $(1 \mathrm{mg} / \mathrm{mL})$ and nitro blue tetrazolium (NBT). The optical densities were estimated at $630 \mathrm{nM}$, and the $\mathrm{IC}_{50}$ values were determined using the GraphPad Prism software version 5 from variable-slope sigmoidal dose-response curves (GraphPad Software Inc., La Jolla, CA, USA).

\subsection{Molecular Docking}

Docking analysis was carried out using the Discovery Studio 2.5 software (Accelrys Inc., San Diego, CA, USA). Completely automatic docking tool using "Dock ligands (CDOCKER)" procedure operating on Intel Core i32370 CPU @ $2.4 \mathrm{GHz} 2.4 \mathrm{GHz}, \mathrm{RAM}$ Memory 2 GB under the Windows 10.0 system. Furthermore, these docked compounds were assembled using a software Chem 3D ultra 12.0 (Cambridge Soft Corporation, USA (2010)), and then sent to the Discovery Studio 2.5 software. From this, an automatic protein formulation procedure was conducted through the MMFF94 forcefield with the binding site sphere recognised by the software. The receptor was recorded as "input receptor molecule" in the CDOCKER protocol explorer. Establishing this, the test compounds were subjected to force fields to obtain the minimum energy structure. These poses were ranked and studied thoroughly, showing the best ligand-HDAC interactions from the calculations and $2 \mathrm{D}$ and 3D examinations $[72,73]$.

\section{Conclusions}

Microbial coculture continues to prove its efficiency in triggering the production of cryptic microbial secondary metabolites. Mixed cultivation of two Red Sea-derived actinobacteria, namely, Actinokineospora spheciospongiae strain EG49 and Rhodococcus sp. UR59, resulted in the induction of several non-traced metabolites in their axenic cultures. Interestingly, actinosporins $\mathrm{E}-\mathrm{H}$ were reported to be induced when the axenic culture of the Actinokineospora spheciospongiae strain EG49 was treated with the signalling molecule GluNAc. Such induction was comparable to that made by the Rhodococcus sp. UR59 in the coculture environment, providing the effectiveness of co-cultivation in the discovery of microbial metabolites yet to be discovered in the axenic fermentation with the potential that could be comparable to adding signalling molecules in the fermentation flask. Additionally, the induced actinosporins exhibited a promising antimalarial effect that is likely to be through the inhibition of P. falciparum lysyl-tRNA synthetase, which requires further investigation as an interesting structural motif for the development of new antimalarial therapeutics.

Author Contributions: Conceptualisation, H.A.A., B.T., U.R.A., and M.E.R.; methodology, H.A.A., B.T., M.H.A.H., F.A.B., C.J.N., and H.M.H.; software, H.A.A. and B.T.; validation, G.P., U.R.A., and M.E.R.; formal analysis, H.A.A., B.T., M.H.A.H., F.A.B., C.J.N., and H.M.H.; data curation, H.A.A. and B.T.; writing-original draft preparation, H.A.A., B.T., M.H.A.H., F.A.B., C.J.N., and H.M.H.; writing-review and editing, G.P., U.R.A., and M.E.R.; supervision, G.P., U.R.A., and M.E.R.; project administration, M.E.R.; funding acquisition, H.A.A. All authors have read and agreed to the published version of the manuscript. 
Funding: This research was funded by the Deanship of Scientific Research (DSR), King Abdulaziz University, Jeddah, under grant no. (DF-316-142-1441). The authors, therefore, gratefully acknowledge DSR technical and financial support.

Institutional Review Board Statement: Not applicable.

Data Availability Statement: No supplementary data available with this article.

Acknowledgments: The authors also like to thank the Deanship of Scientific Research (DSR), King Abdulaziz University, for their technical and financial support.

Conflicts of Interest: The authors declare no conflict of interest.

\section{References}

1. Nai, C.; Meyer, V. From axenic to mixed cultures: Technological advances accelerating a paradigm shift in microbiology. Trends Microbiol. 2018, 26, 538-554. [CrossRef]

2. Wu, C.; Choi, Y.H.; van Wezel, G.P. Metabolic profiling as a tool for prioritising antimicrobial compounds. J. Ind. Microbiol. 2006, 43, 299-312.

3. Watve, M.G.; Tickoo, R.; Jog, M.M.; Bhole, B.D. How many antibiotics are produced by the genus Streptomyces? Arch. Microbiol. 2001, 176, 386-390. [CrossRef] [PubMed]

4. Harvey, A.L.; Edrada-Ebel, R.; Quinn, R.J. The re-emergence of natural products for drug discovery in the genomics era. Nat. Rev. Drug Discov. 2015, 14, 111-129. [CrossRef]

5. Sanchez, J.F.; Somoza, A.D.; Keller, N.P.; Wang, C.C. Advances in Aspergillus secondary metabolite research in the post-genomic era. Nat. Prod. Rep. 2012, 29, 351-371. [CrossRef] [PubMed]

6. Inglis, D.O.; Binkley, J.; Skrzypek, M.S.; Arnaud, M.B.; Cerqueira, G.C.; Shah, P.; Wymore, F.; Wortman, J.R.; Sherlock, G. Comprehensive annotation of secondary metabolite biosynthetic genes and gene clusters of Aspergillus nidulans, A. fumigatus, A. niger and A. oryzae. BMC Microbiol. 2013, 13, 91. [CrossRef]

7. Brakhage, A.A. Regulation of fungal secondary metabolism. Nat. Rev. Microbiol. 2013, 11, 21-32. [CrossRef]

8. Bednarski, Z.; Bednarska, H. First research work by Robert Koch on etiology of anthrax-in cooperation with Józef Knechtel, Polish apothecary. Arch. Hist. Filoz. Med. 2003, 66, 161-168.

9. Fischer, A. Acid production graphically registered as an indicator of the vital processes in the cultivation of bacteria. J. Exp. Med. 1918, 28, 529-545. [CrossRef]

10. Degenkolb, T.; Heinze, S.; Schlegel, B.; Strobel, G.; Gräfe, U. Formation of new lipoaminopeptides, acremostatins A, B, and C, by co-cultivation of Acremonium sp. Tbp-5 and Mycogone rosea DSM 12973. Biosci. Biotechnol. Biochem. 2002, 6, 883-886. [CrossRef] [PubMed]

11. Wakefield, J.; Hassan, H.M.; Jaspars, M.; Ebel, R.; Rateb, M.E. Dual induction of new microbial secondary metabolites by fungal bacterial co-cultivation. Front. Microbiol. 2017, 8, 1284. [CrossRef] [PubMed]

12. Li, C.; Sarotti, A.M.; Yang, B.; Turkson, J.; Cao, S. A new N-methoxypyridone from the co-cultivation of Hawaiian endophytic fungi Camporesia sambuci FT1061 and Epicoccum sorghinum FT1062. Molecules 2017, 22, 1166. [CrossRef]

13. Thissera, B.; Alhadrami, H.A.; Hassan, M.H.; Hassan, H.M.; Bawazeer, M.; Yaseen, M.; Belbahri, L.; Rateb, M.E.; Behery, F.A. Induction of cryptic antifungal pulicatin derivatives from Pantoea agglomerans by microbial coculture. Biomolecules 2020, 10, 268. [CrossRef] [PubMed]

14. Dobson, M.J. Exploring natural remedies from the past. Parassitologia 1998, 40, 69-81.

15. Pyae Phyo, A.; Nkhoma, S.; Singhasivanon, P.; Day, N.P.; White, N.J. Emergence of artemisinin-resistant malaria on the western border of Thailand: A longitudinal study. Lancet 2012, 379, 1960-1966. [CrossRef]

16. Straimer, J.; Gnädig, N.F.; Witkowski, B.; Amaratunga, C.; Duru, V.; Ramadani, A.P.; Dacheux, M.; Khim, N.; Zhang, L.; Lam, S.; et al. K13-propeller mutations confer artemisinin resistance in Plasmodium falciparum clinical isolates. Science 2015, 347, 428-431. [CrossRef] [PubMed]

17. Yeka, A.; Lameyre, V.; Afizi, K.; Fredrick, M.; Lukwago, R.; Kamya, M.R.; Talisuna, A.O. Efficacy and safety of fixed-dose artesunate-amodiaquine vs. artemether-lumefantrine for repeated treatment of uncomplicated malaria in Ugandan children. PLoS ONE 2014, 9, e113311. [CrossRef]

18. Abdelmohsen, U.R.; Pimentel-Elardo, S.M.; Hanora, A.; Radwan, M.; Abou-El-Ela, S.H.; Ahmed, S.; Hentschel, U. Isolation, phylogenetic analysis and anti-infective activity screening of marine sponge-associated actinomycetes. Mar. Drugs 2010, 8, 399-412. [CrossRef] [PubMed]

19. Kampfer, P.; Glaeser, S.P.; Busse, H.J.; Abdelmohsen, U.R.; Ahmed, S.; Hentschel, U. Actinokineospora spheciospongiae sp. nov., isolated from the marine sponge Spheciospongia vagabunda. Int. J. Syst. Evol. Microbiol. 2015, 65 Pt 3, 879-884. [CrossRef]

20. Bass, P.D.; Gubler, D.A.; Judd, T.C.; Williams, R.M. Mitomycinoid alkaloids: Mechanism of action, biosynthesis, total syntheses, and synthetic approaches. Chem. Rev. 2013, 113, 6816-6863. [CrossRef] 
21. Gu, Q.S.; Yang, D. Enantioselective Synthesis of (+)-Mitomycin K by a Palladium-Catalysed Oxidative Tandem Cyclization. Angew. Chem. 2017, 129, 5980-5983. [CrossRef]

22. Akiyama, T.; Harada, S.; Kojima, F.; Takahashi, Y.; Imada, C.; Okami, Y.; Muraoka, Y.; Aoyagi, T.; Takeuchi, T. Fluostatins A and B, New Inhibitors of Dipeptidyl Peptidase III, Produced by Streptomyces sp. TA-3391. J. Antibiot. 1998, 51, 553-559. [CrossRef]

23. Abdelmohsen, U.R.; Cheng, C.; Viegelmann, C.; Zhang, T.; Grkovic, T.; Ahmed, S.; Quinn, R.J.; Hentschel, U.; Edrada-Ebel, R. Dereplication strategies for targeted isolation of new antitrypanosomal actinosporins A and B from a marine sponge associatedActinokineospora sp. EG49. Mar. Drugs 2014, 12, 1220-1244. [CrossRef]

24. Grkovic, T.; Abdelmohsen, U.R.; Othman, E.M.; Stopper, H.; Edrada-Ebel, R.; Hentschel, U.; Quinn, R.J. Two new antioxidant actinosporin analogues from the calcium alginate beads culture of sponge-associated Actinokineospora sp. strain EG49. Bioorg. Med. Chem. Lett. 2014, 24, 5089-5092. [CrossRef] [PubMed]

25. Blumauerova, M.; Kralovcova, E.; Matějů, J.; Jizba, J.; Vaněk, Z. Biotransformations of anthracyclinones in Streptomyces coeruleorubidus and Streptomyces galilaeus. Folia Microbiol. 1979, 24, 117. [CrossRef]

26. Fujioka, K.; Furihata, K.; Shimazu, A.; Hayakawa, Y.; Seto, H. Isolation and characterisation of atramycin A and atramycin B, new isotetracenone type antitumor antibiotics. J. Antibiot. 1991, 44, 1025-1028. [CrossRef]

27. Mullowney, M.W.; Ó hAinmhire, E.; Tanouye, U.; Burdette, J.E.; Pham, V.C.; Murphy, B.T. A Pimarane Diterpene and Cytotoxic Angucyclines from a Marine-Derived Micromonospora sp. in Vietnam's East Sea. Mar. Drugs 2015, 13, 5815-5827. [CrossRef] [PubMed]

28. Huang, R.; Ding, Z.G.; Long, Y.F.; Zhao, J.Y.; Li, M.G.; Cui, X.L.; Wen, M.L. A new isoflavone derivative from Streptomyces sp. YIM GS3536. Chem. Nat. Compd. 2013, 48, 966-969. [CrossRef]

29. Maskey, R.P.; Asolkar, R.N.; Speitling, M.; Hoffman, V.; Grün-Wollny, I.; Fleck, W.F.; Laatsch, H. Flavones and new isoflavone derivatives from microorganisms: Isolation and structure elucidation. Z. Naturforsch. B 2003, 58, 686-691. [CrossRef]

30. Sugumaran, M.; Robinson, W.E. Bioactive dehydrotyrosyl and dehydrodopyl compounds of marine origin. Mar. Drugs 2010, 8, 2906-2935. [CrossRef]

31. Umezawa, H.; Imoto, M.; Sawa, T.; Isshiki, K.; Matsuda, N.; Uchida, T.; Iinuma, H.; Hamada, M.; Takeuchi, T. Studies on a new epidermal growth factor-receptor kinase inhibitor, erbstatin, produced by MH435-hF3. J. Antibiot. 1986, 39, 170-173. [CrossRef]

32. Weber, W.; Zähner, H.; Damberg, M.; Russ, P.; Zeeck, A. Metabolic products of microorganisms 201. Ansatrienin A and B, antifungal antibiotics from Streptomyces collinus. Zentralblatt für Bakteriologie Mikrobiologie und Hygiene: I. Abt. Orig. C Allg. Angew. Okol. Mikrobiol. 1981, 2, 122-139.

33. Chiba, H.; Agematu, H.; Kaneto, R.; Terasawa, T.; Sakai, K.; Dobashi, K.; Yoshioka, T. Rhodopeptins (Mer-N1033), Novel Cyclic Tetrapeptides with Antifungal Activity from Rhodococcus sp. J. Antibiot. 1999, 52, 695-699. [CrossRef]

34. Nakayama, K.; Kawato, H.C.; Inagaki, H.; Nakajima, R.; Kitamura, A.; Someya, K.; Ohta, T. Synthesis and antifungal activity of rhodopeptin analogues. 2. Modification of the west amino acid moiety. Org. Lett. 2000, 2, 977-980. [CrossRef]

35. Nam, S.J.; Kauffman, C.A.; Jensen, P.R.; Fenical, W. Isolation and characterization of actinoramides A-C, highly modified peptides from a marine Streptomyces sp. Tetrahedron 2011, 67, 6707-6712. [CrossRef] [PubMed]

36. Terekhova, L.P.; Galatenko, O.A.; Kulyaeva, V.V.; Malkina, N.D.; Boikova, Y.V.; Katrukha, G.S.; Shashkov, A.S.; Gerbst, A.G.; Nifantiev, N.E. Isolation, NMR spectroscopy, and conformational analysis of the antibiotic ina 2770 (cineromycin B) produced by Streptomyces strain. Russ. Chem. 2007, 56, 815-818. [CrossRef]

37. Carrano, C.J.; Jordan, M.; Drechsel, H.; Schmid, D.G.; Winkelmann, G. Heterobactins: A new class of siderophores from Rhodococcus erythropolis IGTS8 containing both hydroxamate and catecholate donor groups. Biometals 2001, 14, 119-125. [CrossRef]

38. Han, X.; Liu, Z.; Zhang, Z.; Zhang, X.; Zhu, T.; Gu, Q.; Li, W.; Che, Q.; Li, D. Geranylpyrrol A and Piericidin F from Streptomyces sp. CHQ-64 $\Delta$ rdmF. J. Nat. Prod. 2017, 80, 1684-1687. [CrossRef]

39. Nakae, K.; Yoshimoto, Y.; Ueda, M.; Sawa, T.; Takahashi, Y.; Naganawa, H.; Takeuchi, T.; Imoto, M. Migrastatin, a novel 14-membered lactone from Streptomyces sp. MK929-43F1. J. Antibiot. 2000, 53, 1228-1230. [CrossRef] [PubMed]

40. Chen, L.Y.; Wang, X.Q.; Wang, Y.M.; Geng, X.; Xu, X.N.; Su, C.; Yang, Y.L.; Tang, Y.J.; Bai, F.W.; Zhao, X.Q. Genome mining of Streptomyces xinghaiensis NRRL B-24674 T for the discovery of the gene cluster involved in anticomplement activities and detection of novel xiamycin analogs. Appl. Microbiol. Biotechnol. 2018, 102, 9549-9562. [CrossRef] [PubMed]

41. Omura, S.; Matsubara, H.; Nakagawa, A.; Furusaki, A.; Matsumoto, T. X-Ray crystallography of protylonolide and absolute configuration of tylosin. J. Antibiot. 1980, 33, 915-917. [CrossRef]

42. Gräfe, U.; Schlegel, R.; Stengel, C.; Ihn, W.; Radics, L. Isolation and structure of 26-deoxylaidlomycin, a new polyether antibiotic from Streptoverticillium olivoreticuli. J. Basic Microbiol. 1989, 29, 149-155. [CrossRef]

43. Hirota, A.; Okada, H.; Kanza, T.; Isogai, A.; Hirota, H. Structure elucidation of kaimonolide B, a new plant growth inhibitor macrolide from Streptomyces. Agric. Biol. Chem. 1990, 54, 2489-2490. [CrossRef]

44. Arakawa, K. Genetic and biochemical analysis of the antibiotic biosynthetic gene clusters on the Streptomyces linear plasmid. Biosci. Biotechnol. Biochem. 2014, 78, 183-189. [CrossRef]

45. Kusakabe, Y.; Mizuno, T.; Kawabata, S.; Tanji, S.; Seino, A.; Seto, H.; Otake, N. Ferensimycins A and B, two polyether antibiotics. J. Antibiot. 1982, 35, 1119-1129. [CrossRef]

46. Cho, J.Y.; Williams, P.G.; Kwon, H.C.; Jensen, P.R.; Fenical, W. Lucentamycins A-D, cytotoxic peptides from the marine-derived actinomycete Nocardiopsis lucentensis. J. Nat. Prod. 2007, 70, 1321-1328. [CrossRef] [PubMed] 
47. Qian-cutrone, J.; Ueki, T.; Huang, S.; MookhtiaR, K.A.; Ezekiel, R.; Kalinowski, S.S.; Brown, K.S.; Golik, J.; Lowe, S.; Pirnik, D.M.; et al. Glucolipsin A and B, two new glucokinase activators produced by Streptomyces purpurogeniscleroticus and Nocardia vaccinii. J. Antibiot. 1999, 52, 245-255. [CrossRef]

48. Howlett, D.R.; George, A.R.; Owen, D.E.; Ward, R.V.; Markwell, R.E. Common structural features determine the effectiveness of carvedilol, daunomycin and rolitetracycline as inhibitors of Alzheimer $\beta$-amyloid fibril formation. Biochem. J. 1999, 343, 419-423. [CrossRef]

49. Dashti, Y.; Grkovic, T.; Abdelmohsen, U.R.; Hentschel, U.; Quinn, R.J. Actinomycete metabolome induction/suppression with N-Acetylglucosamine. J. Nat. Prod. 2017, 80, 828-836. [CrossRef]

50. Inahashi, Y.; Iwatsuki, M.; Ishiyama, A.; Namatame, M.; Nishihara-Tsukashima, A.; Matsumoto, A.; Hirose, T.; Sunazuka, T.; Yamada, H.; Otoguro, K.; et al. Spoxazomicins A-C, novel antitrypanosomal alkaloids produced by an endophytic actinomycete, Streptosporangium oxazolinicum K07-0460 T. J. Antibiot. 2011, 64, 303-307. [CrossRef]

51. Cheng, K.C.C.; Cao, S.; Raveh, A.; MacArthur, R.; Dranchak, P.; Chlipala, G.; Okoneski, M.T.; Guha, R.; Eastman, R.T.; Yuan, J.; et al. Actinoramide A identified as a potent antimalarial from titration-based screening of marine natural product extracts. J. Nat. Prod. 2015, 78, 2411-2422. [CrossRef]

52. Elleuch, L.; Shaaban, M.; Smaoui, S.; Mellouli, L.; Karray-Rebai, I.; Fguira, L.F.B.; Shaaban, K.A.; Laatsch, H. Bioactive secondary metabolites from a new terrestrial Streptomyces sp. TN262. Appl. Biochem. Biotechnol. 2010, 162, 579-593. [CrossRef]

53. Giralt, E.; Lo Re, D. The therapeutic potential of migrastatin-core analogs for the treatment of metastatic cancer. Molecules 2017, 22, 198. [CrossRef]

54. Ujikawa, K.; Vilegas, W.; Vilegas, J.H.; Llabrés, G. Antibiotic 26-deoxylaidlomycin isolated from Streptomyces sp. Ar386 from Brazilian soil. Rev. Latinoam. Microbiol. 1996, 38, 185-191. [PubMed]

55. Le, T.V.; Hanh, T.T.H.; Huong, P.T.T.; Dang, N.H.; Van Thanh, N.; Cuong, N.X.; Nam, N.H.; Thung, D.C.; Van Kiem, P.; Van Minh, C. Anthraquinone and butenolide constituents from the crinoid Capillaster multiradiatus. Chem. Pharm. Bull. 2018, $66,1023-1026$.

56. Kuntsmann, M.P.; Mitscher, L.A. The Structural Characterization of Tetrangomycin and Tetrangulol. J. Org. Chem. 1966, 31, 2920-2925. [CrossRef] [PubMed]

57. Ukei, M.; Abe, K.; Hanafi, M.; Shibata, K.; Tanaka, T.; Tanaiguchi, M. UK-2 A, B, C and D Novel antifungal antibiotics from Streptomyces sp. 517-02. J. Antibiot. 1996, 49, 639-643. [CrossRef]

58. Guo, Z.K.; Wang, T.; Guo, Y.; Song, Y.C.; Tan, R.X.; Ge, H.M. Cytotoxic angucyclines from Amycolatopsis sp. HCa1, a rare actinobacteria derived from Oxya chinensis. Planta Med. 2011, 77, 2057. [CrossRef]

59. Hanafi, M.; Shibata, K.; Ueki, M.; Taniguchi, M. UK-2A, B, C and D, Novel Antifungal Antibiotics from Streptomyces sp. 517-02. J. Antibiot. 1996, 49, 1226-1231. [CrossRef] [PubMed]

60. Konopka, J.B. N-acetylglucosamine functions in cell signalling. Scientifica 2012, 2012, 489208. [CrossRef]

61. Naseem, S.; Parrino, S.M.; Buenten, D.M.; Konopka, J.B. Novel roles for GlcNAc in cell signalling. Commun. Integr. Biol. 2012, 5, 156-159. [CrossRef] [PubMed]

62. Rigali, S.; Nothaft, H.; Noens, E.E.; Schlicht, M.; Colson, S.; Müller, M.; Joris, B.; Koerten, H.K.; Hopwood, D.A.; Titgemeyer, F; et al. The sugar phosphotransferase system of Streptomyces coelicolor is regulated by the GntR-family regulator DasR and links N-acetylglucosamine metabolism to the control of development. Mol. Microbiol. 2006, 61, 1237-1251. [CrossRef] [PubMed]

63. Boonlarppradab, C.; Suriyachadkun, C.; Rachtawee, P.; Choowong, W. Saccharosporones A, B and C, cytotoxic antimalarial angucyclinones from Saccharopolyspora sp. BCC 21906. J. Antibiot. 2013, 266, 305-309. [CrossRef] [PubMed]

64. Carr, G.; Derbyshire, E.R.; Caldera, E.; Currie, C.R.; Clardy, J. Antibiotic and antimalarial quinones from fungus-growing ant-associated Pseudonocardia sp. J. Nat. Prod. 2012, 75, 1806-1809. [CrossRef] [PubMed]

65. Supong, K.; Thawai, C.; Suwanborirux, K.; Choowong, W.; Supothina, S.; Pittayakhajonwut, P. Antimalarial and antitubercular C-glycosylated benz $[\alpha]$ anthraquinones from the marine-derived Streptomyces sp. BCC45596. Phytochem. Lett. 2012, 5, 651-656. [CrossRef]

66. Baragaña, B.; Forte, B.; Choi, R.; Hewitt, S.N.; Bueren-Calabuig, J.A.; Pisco, J.P.; Norcross, N.R. Lysyl-tRNA synthetase as a drug target in malaria and cryptosporidiosis. Proc. Natl. Acad. Sci. USA 2019, 116, 7015-7020. [CrossRef] [PubMed]

67. Ashelford, K.E.; Chuzhanova, N.A.; Fry, J.C.; Jones, A.J.; Weightman, A.J. At least 1 in $2016 \mathrm{~S}$ rRNA sequence records currently held in public repositories is estimated to contain substantial anomalies. Appl. Environ. Microbiol. 2005, 71, 7724-7736. [CrossRef] [PubMed]

68. Pruesse, E.; Peplies, J.; Glockner, F.O. SINA: Accurate high-throughput multiple sequence alignment of ribosomal RNA genes. Bioinformatics 2012, 28, 1823-1829. [CrossRef]

69. Letunic, I.; Bork, P. Interactive Tree of Life v2: Online annotation and display of phylogenetic trees made easy. Nucleic Acids Res. 2011, 39, W475-W478. [CrossRef]

70. Ngwa, C.J.; Kiesow, M.J.; Papst, O.; Orchard, L.M.; Filarsky, M.; Rosinski, A.N.; Voss, T.S.; Llinás, M.; Pradel, G. Transcriptional profiling defines histone acetylation as a regulator of gene expression during human-to-mosquito transmission of the malaria parasite Plasmodium falciparum. Front. Cell. Infect. Microbiol. 2017, 7, 320. [CrossRef]

71. Basova, S.; Wilke, N.; Koch, J.C.; Prokop, A.; Berkessel, A.; Pradel, G.; Ngwa, C.J. Organoarsenic Compounds with in vitro Activity against the Malaria Parasite Plasmodium falciparum. Biomedicines 2020, 8, 260. [CrossRef] [PubMed] 
72. Sayed, A.M.; Alhadrami, H.A.; El-Gendy, A.O.; Shamikh, Y.I.; Belbahri, L.; Hassan, H.M.; Rateb, M.E. Microbial natural products as potential inhibitors of SARS-CoV-2 main protease (Mpro). Microorganisms 2020, 8, 970. [CrossRef] [PubMed]

73. Sayed, A.M.; Alhadrami, H.A.; El-Hawary, S.S.; Mohammed, R.; Hassan, H.M.; Rateb, M.E.; Bakeer, W. Discovery of two brominated oxindole alkaloids as Staphylococcal DNA gyrase and pyruvate kinase inhibitors via inverse virtual screening. Microorganisms 2020, 8, 293. [CrossRef] [PubMed] 